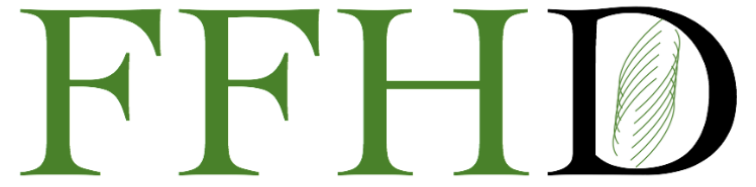

Functional Foods in Health and Disease

\title{
An in vitro study to explore the modulation of eosinophil effector function in human allergic peripheral blood eosinophils using enzymatically extracted salmonid oil
}

\section{Bomi Framroze*and Henriette Heggdal}

Hofseth Biocare AS, Havnegata 11, Aalesund 6005, Norway

*Corresponding Author: Bomi Framroze, Hofseth Biocare AS, Havnegata 11, Aalesund 6005, Norway

Submission Date: July 11 ${ }^{\text {th }}, 2020$; Acceptance Date: August $25^{\text {th }}, 2020$; Publication Date: August $31^{\text {st }}, 2020$

Please cite this article as: Heggdal H., Framroze B. An in vitro study to explore the modulation of eosinophil effector function in human allergic peripheral blood eosinophils using enzymatically extracted salmonid oil. Functional Foods in Health and Disease 2020; 10(8): 257-367. DOI: https://www.doi.org/10.31989/ffhd.v10i8.730

\footnotetext{
ABSTRACT

Background: The consumption of oily fish in early childhood diets has been correlated to a reduction in the progression of asthma during adolescence and young adulthood. Extending these results to studies on supplementation with omega-3 fish oils has led to equivocal results, with no clear results. One subset of asthma patients is classified as steroid-treatment resistant, which may be attributable to eosinophil dysfunction. This in-vitro study investigated the prophylactic effect of enzymatically extracted salmon oil, as a proxy for eating fresh whole oily fish, on eosinophil function using allergic human peripheral blood eosinophils.

Methods: We measured three eosinophil effector functions in allergic human peripheral blood eosinophils after prophylactic treatment with enzymatically extracted salmonid oil. We measured changes in: i) eosinophil shape change in normal PMNL ii) integrin

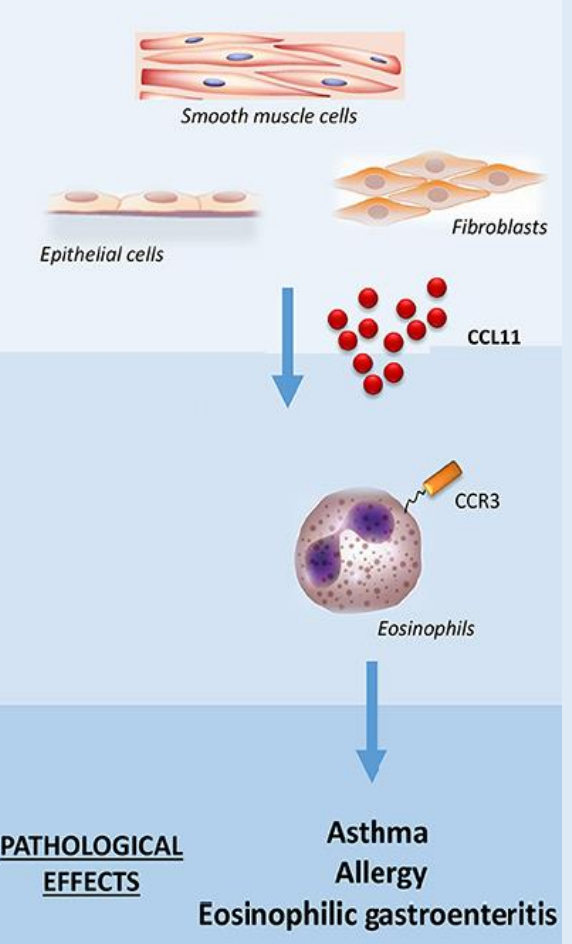
upregulation in normal PMNL and iii) eosinophil apoptosis. We further measured changes in these functions after prophylactic treatment with omega-3 fish oil, krill oil, and fractions of the salmon oil subjected to several commercial fish oil processing conditions.
} 
Results: Prophylactic treatment of allergic human peripheral blood eosinophil with $100 \mathrm{ug} / \mathrm{ml}$ of enzymatically extracted salmonid oil showed modulation of eosinophil effect functions and apoptosis comparable to APOA-IV at $3 \mathrm{ug} / \mathrm{ml}$. Vigorous processing conditions applied to the salmon oil degraded the observed eosinophil modulation. Krill oil and standard fish oil showed no to low eosinophil modulation.

Conclusions: Enzymatically extracted salmonid oil demonstrates potential therapeutic promise for the treatment of eosinophil effector malfunction-based allergic and inflammatory conditions, particularly certain types of asthma and COPD. Treatment of the oil with commercial marine oil processing conditions significantly reduces or eliminates this eosinophil effector function modulation.

Keywords: Eosinophils, asthma, salmon oil, APOA-IV, apoptosis

CFFC 2020. This is an Open Access article distributed under the terms of the Creative Commons Attribution 4.0 License (http://creativecommons.org/licenses/by/4.0)

\section{INTRODUCTION}

Inflammation is an immunological balancing act. On the one hand, the physiological changes that accompany inflammation allow us to mount an acute response to external threats that can lead to pandemics, such as the current SARS-Cov-2 infection, while on the other hand, chronic inflammation, where age or external stressors keep our immune system in exaggerated overdrive, contributes to many debilitating diseases ranging from Alzheimer's to diabetes to bronchial asthma.

Fish oil supplementation for the potential control of bronchial asthma symptoms has been described in numerous publications [1][2]. Although early studies suggested that long-chain $n-3$ polyunsaturated fatty acids (LCn3PUFAs) found in standard fish oils may reduce the risk and symptoms of asthma, the epidemiological data with fish oil supplementation remains inconclusive. One potential reason is that the fish oil clinical studies did not separate patients into the many different causes of asthma using specific inflammatory biomarkers to guide patient selection and recruitment [3][4].
Yet, it is also apparent that despite the same lack of patient selectivity, the epidemiological evidence that eating whole oily fish, particularly early in life, helps reduce the risk and severity of asthma during childhood development is more consistently positive [5][6]. It is possible that the process of manufacturing commercial omega-3 fish oils destroys some or all of the minor components that are present in the natural fresh fish accounting for this discrepancy in improved asthma control.

Eosinophils are potent activators and modulators of diseases such as bronchial asthma [7] atopic dermatitis [8], and colitis ulcerosa [9]. In a subset of asthmatic patients, increased levels of chemotactic activation, eosinophil granule proteins, and decreased eosinophil apoptosis largely correlates with asthma severity [10].The activated eosinophils, which are promoted by eosinophil-activating cytokines under inflammatory conditions, are a major source of ROS and cytotoxic proteins [11]. This eosinophilic activation of resident tissue cells, such as epithelial, endothelial and fibroblast cells, leads to an increase of inflammation and mucus secretion during 
an asthmatic event [12]. Due to this different mechanism of activation of asthma, these patients do not respond well, if at all, to standard steroid therapy and are referred to as steroid-treatment resistant asthmatics [13][14].

An eosinophil is a type of white blood cell stored in tissues throughout the body and is continually replenished from the bone marrow. An eosinophil count is a blood test that measures the quantity of eosinophils in your body. Elevated levels, usually measured during routine $\mathrm{CBC}$ testing, indicate an infection or allergy. Eosinophils typically have a twoday lifespan in blood, but inflammatory conditions such as infections and allergic diseases extend the lifespan up to two weeks by eosinophil-activating cytokines. Beta-adrenoreceptor agonists are commonly prescribed for asthma treatment and have been shown to inhibit release of eosinophil-activating cytokines from human airway smooth muscle cells [15].

Of particular note is the observation that eosinophilic inflammation of the upper airways can also occur independent of allergies, as observed in chronic rhinosinusitis (CRS) subjects [16]. Eosinophil dysfunctional asthmatic individuals represent a unique subgroup who are largely resistant to medical and surgical interventions and who may show immediate benefit by therapy that targets eosinophilic expansion and effector functions.

This study was carried out to primarily explore the prophylactic anti-inflammatory effect of enzymatically extracted, unrefined, fresh salmonid oil, used as a proxy for eating natural fresh oily fish, to reduce eosinophil effector function in allergic human peripheral blood eosinophils.

We further compared this eosinophil effector function modulation against the effect of omega-3 fish oil, krill oil, and salmon oil after pre-treatment with commercial fish oil processing conditions (heat, acid, and base) at a $100 \mathrm{ug} / \mathrm{ml}$ concentration with APOA-IV (3ug/ml) as the positive control. We measured three eosinophil effector functions in this study: i) eosinophil shape change in normal PMNL ii) integrin upregulation in normal PMNL and iii) eosinophil apoptosis using APOA-IV at $3 \mathrm{ug} / \mathrm{ml}$ as the positive control.

Our data positively indicates that enzymatically extracted salmonid oil has the potential to impact eosinophilic inflammation and have beneficial effects on eosinophil-driven diseases such as asthma and COPD. A follow-up animal trial using peritoneal fluid eosinophils in guinea pigs is on-going.

\section{METHODS AND MATERIALS}

Chemicals and Reagents: Enzymatically extracted salmonid oil was provided by Hofseth Biocare AS, Norway as an orange liquid, Batch No.B-13606. Fish oil and krill oil was purchased from Costco Inc. in capsules and the oil removed and used as is.

Allergic Human Peripheral Blood Eosinophils (AHPBE) (> 98\% purity) were sourced from Human Cell Biosciences (San Jose, California).

Assay buffer was made from Dulbecco's modified PBS (with $0.9 \mathrm{mmol} / \mathrm{L} \mathrm{Ca2++} 0.5 \mathrm{mmol} / \mathrm{L} \mathrm{Mg} 2+$.

CCL11 was sourced from ImmunoTools (Friesoythe, Germany).

Anti-CD16-PE-Cy5, and anti-CD11b-PE (ICRF44) antibodies were sourced from Thermofisher (USA)

All other reagents were sourced from Sigma Aldrich (USA).

\section{Preparation of Test Article solutions}

(i) Preparation of Enzymatically extracted salmonid oil solution - SO: 1.000 gram of enzymatically extracted salmonid oil was dissolved in $1 \mathrm{ml}$ of DMSO and diluted with Dulbecco's phosphatebuffered saline solution to make exactly $100 \mathrm{ml}$ of 
stock solutions. Further sequential dilutions were carried out using Dulbecco's phosphate-buffered saline from the stock solution to arrive at the desired $100 \mathrm{ug} / \mathrm{ml}$ concentration of enzymatically extracted salmonid oil.

(ii) Preparation of fish oil solution - FO: 1.000 gram of fish oil was dissolved in $1 \mathrm{ml}$ of DMSO and diluted with Dulbecco's phosphate-buffered saline solution to make exactly $100 \mathrm{ml}$ of stock solutions. Further sequential dilutions were carried out using Dulbecco's phosphate-buffered saline from the stock solution to arrive at the desired $100 \mathrm{ug} / \mathrm{ml}$ concentration of fish oil.

(iii) Preparation of krill oil - KO: 1.000 gram of krill oil was dissolved in $1 \mathrm{ml}$ of DMSO and diluted with Dulbecco's phosphate-buffered saline solution to make exactly $100 \mathrm{ml}$ of stock solutions. Further sequential dilutions were carried out using Dulbecco's phosphate-buffered saline from the stock solution to arrive at the desired $100 \mathrm{ug} / \mathrm{ml}$ concentration of krill oil.

(iv) Preparation of Heat-Treated salmonid oil solution - SOHT: 10 grams of enzymatically extracted salmon oil was placed in a round bottom flask purged with nitrogen and heated for 15 minutes at $130^{\circ} \mathrm{C}$. The oil was cooled to room temperature and 1.000 gram of the oil was dissolved in $1 \mathrm{ml}$ of DMSO and diluted with Dulbecco's phosphate-buffered saline solution to make exactly $100 \mathrm{ml}$ of stock solutions. Further sequential dilutions were carried out using Dulbecco's phosphate-buffered saline from the stock solution to arrive at the desired $100 \mathrm{ug} / \mathrm{ml}$ concentration of heat-treated salmon oil.

(v) Preparation of Acid-Treated salmonid oil solution - SOAT: 10 grams of enzymatically extracted salmon oil was placed in a round bottom flask purged with nitrogen and to this was added $10 \mathrm{ml}$ of $3 \mathrm{~N}$ hydrochloric acid solution. Stirred at $25^{\circ} \mathrm{C}$ for 15 minutes. The suspension was centrifuged at 400g for 1 minute and the oil layer removed. 1.000 gram of the oil was dissolved in $1 \mathrm{ml}$ of DMSO and diluted with Dulbecco's phosphatebuffered saline solution to make exactly $100 \mathrm{ml}$ of stock solutions. Further sequential dilutions were carried out using Dulbecco's phosphate-buffered saline from the stock solution to arrive at the desired $100 \mathrm{ug} / \mathrm{ml}$ concentration of acid-treated salmon oil.

(vi) Preparation of Base-Treated salmonid oil solution - SOBT: 10 grams of enzymatically extracted salmon oil was placed in a round bottom flask purged with nitrogen and to this was added $10 \mathrm{ml}$ of $3 \mathrm{~N}$ sodium hydroxide solution. Stirred at $25^{\circ} \mathrm{C}$ for 15 minutes. The suspension was centrifuged at $400 \mathrm{~g}$ for 1 minute and the oil layer removed. 1.000 gram of the oil was dissolved in $1 \mathrm{ml}$ of DMSO and diluted with Dulbecco's phosphate-buffered saline solution to make exactly $100 \mathrm{ml}$ of stock solutions. Further sequential dilutions were carried out using Dulbecco's phosphate-buffered saline from the stock solution to arrive at the desired $100 \mathrm{ug} / \mathrm{ml}$ concentration of base-treated salmon oil.

All test solutions contained less than $0.5 \%$ of DMSO which is the maximum tolerated DMSO concentration of the allergic human peripheral blood eosinophils.

The formulation control solution was prepared by mixing $5 \mathrm{ml}$ of DMSO in $995 \mathrm{ml}$ of Dulbecco's phosphate-buffered saline. 
Shape change assay: We used the chemotactic factor, CCL11, to prime eosinophils to immediately prepare for diapedesis through the endothelium by rearranging their cytoskeleton. This morphological change was detected by flow cytometry as an increase in the forward scatter properties of these cells.

Eosinophil samples were pretreated with 3 ug/ml ApoA-IV (positive control), 100 ug/ml SO, FO, KO, SOHT, SOAT, SOBT and formulation control for 30 minutes at $25^{\circ} \mathrm{C}$ and stimulated with serial dilutions of CCL11 for $20 \mathrm{~min}$ at $37^{\circ} \mathrm{C}$. Shape change was monitored by flow cytometry as the increase of forward scatter (FSC) and was expressed as a percent of the control response. The eosinophils were distinguishable from neutrophils by their SSC properties and autofluorescence [17].

CD11b (integrin) upregulation assay: Another precondition for eosinophil migration and resultant inflammation is the upregulation of adhesion molecules such as the $\alpha \mathrm{m} \beta 2$ integrin, CD11b. Eosinophil samples were pretreated with $3 \mathrm{ug} / \mathrm{ml}$ ApoA-IV (positive control), $100 \mathrm{ug} / \mathrm{ml} \mathrm{SO}, \mathrm{FO}, \mathrm{KO}$, SOHT, SOAT, SOBT and formulation control for 30 minutes at $25^{\circ} \mathrm{C}$ and incubated with serial dilutions of $\mathrm{CCL} 11$ for $30 \mathrm{~min}$ at $37^{\circ} \mathrm{C}$. Samples were stained with anti-CD16-PE-Cy5 and anti-CD11b-PE (ICRF44) antibodies. Eosinophils were identified as CD16 negative cells. CD11b upregulation was analyzed by flow cytometry [18].

Apoptosis assay: Apoptotic cell death plays an important role in the resolution of inflammatory conditions. The allergic human eosinophils were placed in RPMI 1640 medium supplemented with IL5 (50 pM), 1\% FBS and PenStrep in the presence of 3 ug/ml ApoA-IV (positive control), 100 ug/ml SO, FO, $\mathrm{KO}, \mathrm{SOHT}, \mathrm{SOAT}$, SOBT and formulation control. Aliquots were removed after $18 \mathrm{hr}$ incubation, washed twice in PBS, and resuspended in the binding buffer. The eosinophil cells were stained using the Annexin V-FITC Apoptosis Detection Kit I, (Sigma Aldrich) and immediately analyzed by flow cytometry. Each sample was acquired for $1 \mathrm{~min}$, and the total number of eosinophils gated on a forward scatter/side scatter plot and the percentage of live cells (annexin $\mathrm{V}^{\text {neg }}$ ) and apoptotic cells (annexin $\mathrm{V}^{\text {pos }}$ ) was recorded. Annexin Vneg cells were considered to be live cells and annexin Vpos cells were considered to be apoptotic cells.

\section{RESULTS}

Shape change assay: We measured the effects of prophylactic treatments with $3 \mathrm{ug} / \mathrm{ml}$ ApoA-IV (positive control), $100 \mathrm{ug} / \mathrm{ml} \mathrm{SO}, \mathrm{FO}, \mathrm{KO}, \mathrm{SOHT}$, SOAT, SOBT and formulation control on eosinophil shape change in allergic human peripheral blood eosinophils by flow cytometry. As can be seen in Table 1 and Figure 1 below, $100 \mathrm{ug} / \mathrm{ml}$ of SO resulted in significant modulation of shape change to CCL11 stimulation, which was comparable to APOA-IV. All the other test marine oil solutions showed little to no efficacy as compared to the formulation control.

CD11b upregulation assay: We measured the effects of prophylactic treatments with $3 \mathrm{ug} / \mathrm{ml}$ ApoA-IV (positive control), $100 \mathrm{ug} / \mathrm{ml} \mathrm{SO}, \mathrm{FO}, \mathrm{KO}, \mathrm{SOHT}$, SOAT, SOBT and formulation control on integrin mobilization of allergic human peripheral blood eosinophils by CD11b. The pretreated samples were 
Table 1. Shape Change Assay Results (CCL11 stimulation)

\begin{tabular}{|c|c|c|c|c|c|c|c|c|}
\hline CCL11 (nM) & APOA-IV & SO & FO & SOHT & SOAT & KO & SOBT & Control \\
\hline 0.05 & 100 & 101 & 100 & 100 & 100 & 101 & 99 & 101 \\
\hline 0.10 & 103 & 103 & 104 & 104 & 104 & 104 & 105 & 105 \\
\hline 0.25 & 105 & 106 & 107 & 108 & 109 & 109 & 108 & 109 \\
\hline 0.50 & 106 & 107 & 109 & 112 & 111 & 112 & 112 & 111 \\
\hline 0.75 & 108 & 111 & 117 & 118 & 121 & 120 & 122 & 123 \\
\hline 1.00 & 109 & 111 & 116 & 119 & 118 & 120 & 124 & 122 \\
\hline 2.50 & 109 & 112 & 116 & 117 & 119 & 120 & 120 & 119 \\
\hline 5.00 & 107 & 109 & 114 & 115 & 116 & 118 & 116 & 117 \\
\hline
\end{tabular}

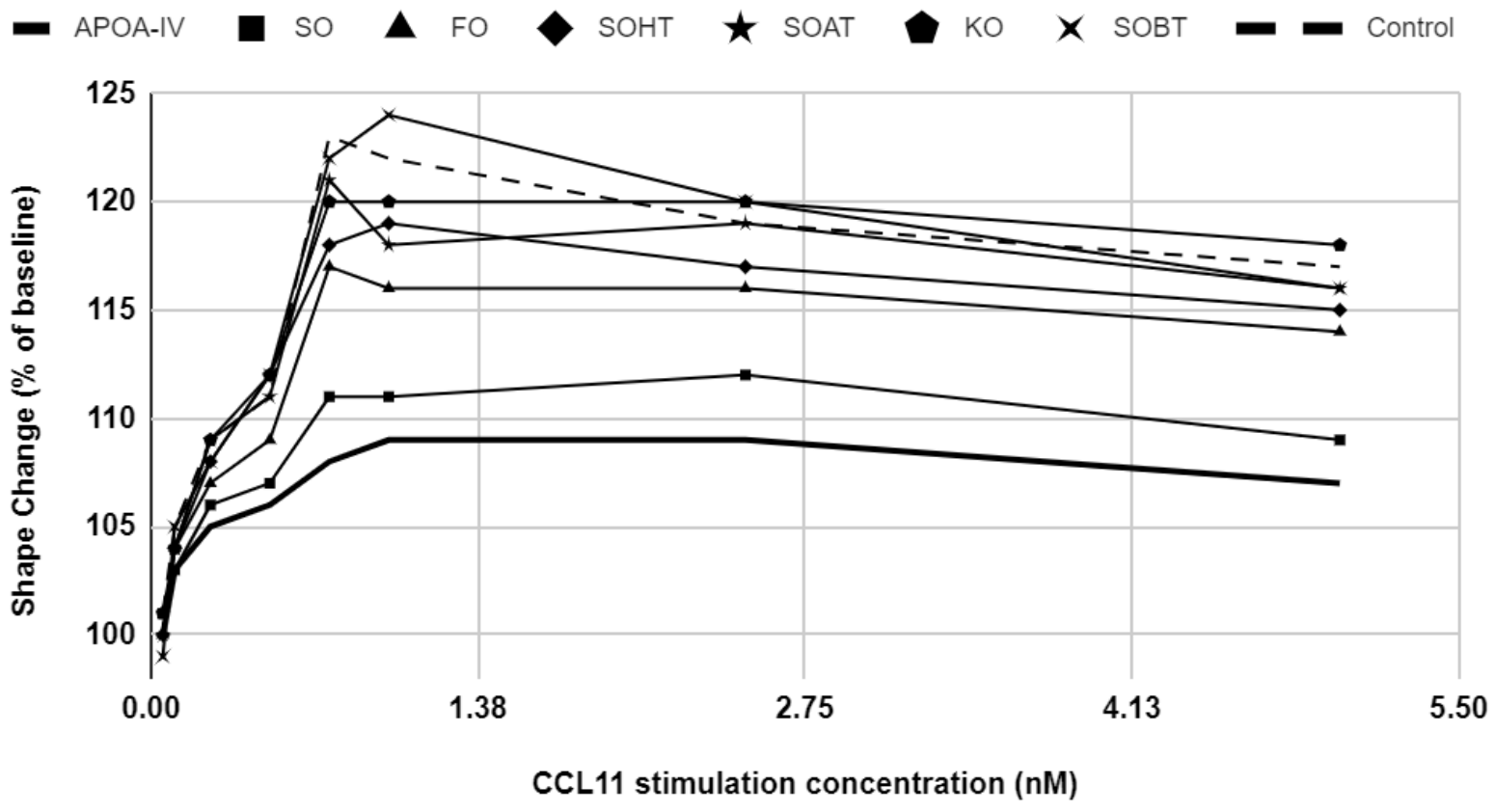

Figure 1. Shape Change Assay (APOA-IV-3ug/ml; Test solutions-100ug/ml) 
Table 2. CD11b upregulation assay results (CCL11 stimulation)

\begin{tabular}{|c|c|c|c|c|c|c|c|c|}
\hline CCL11 (nM) & APOA-IV & SO & FO & SOHT & SOAT & KO & SOBT & Control \\
\hline 0.01 & 95 & 96 & 98 & 100 & 101 & 99 & 100 & 101 \\
\hline 0.50 & 103 & 102 & 104 & 105 & 104 & 103 & 103 & 104 \\
\hline 1.00 & 122 & 121 & 131 & 132 & 135 & 130 & 132 & 134 \\
\hline 2.50 & 125 & 123 & 137 & 140 & 141 & 140 & 141 & 142 \\
\hline 10.00 & 114 & 113 & 131 & 134 & 134 & 130 & 136 & 147 \\
\hline
\end{tabular}

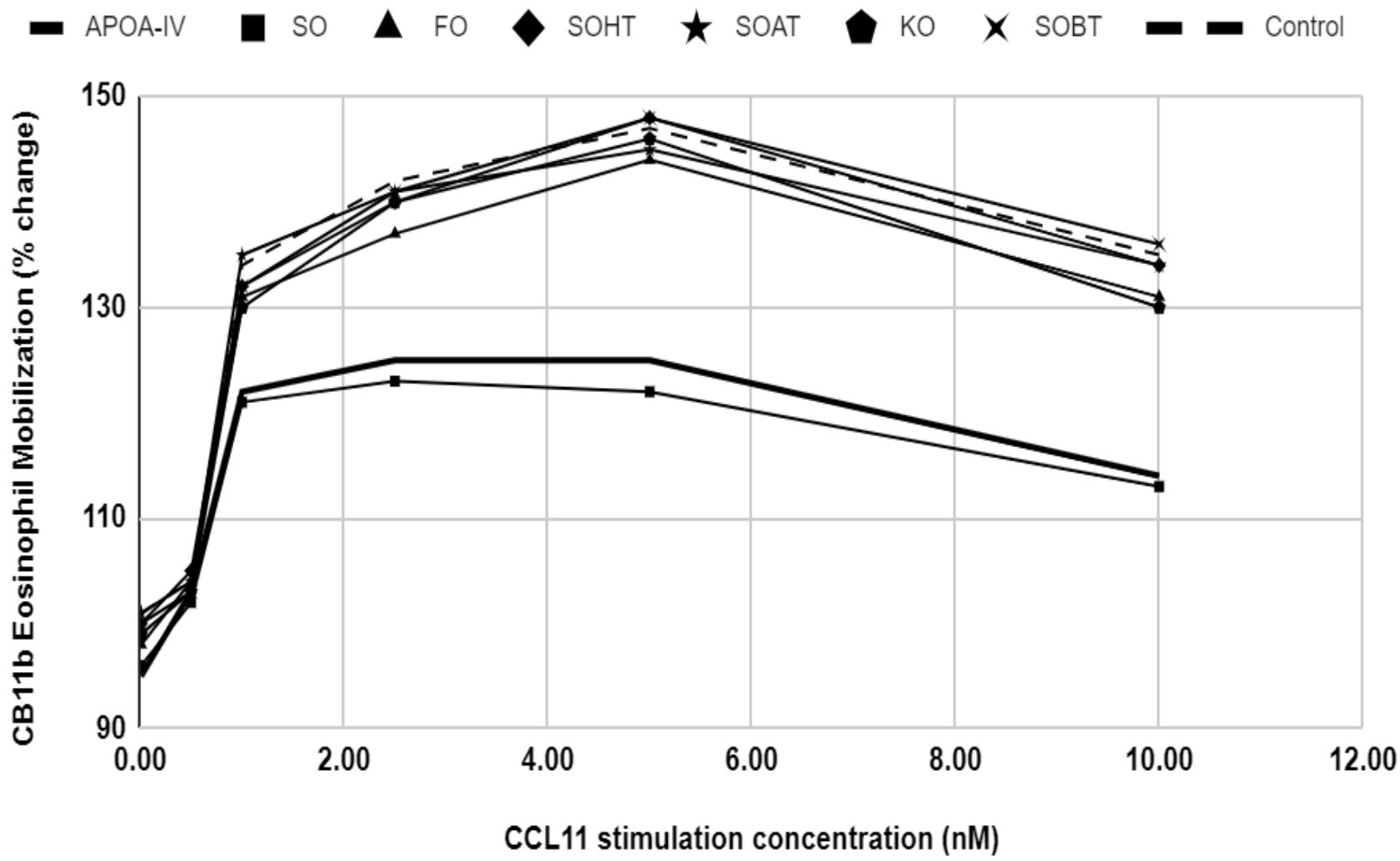

Figure 2. CD11b Percent Change ((APOA-IV - 3ug/ml; Test solutions - 100ug/ml)) 
stimulated with serial dilutions of CCL11. As can be seen in Table 2 and Figure 2 below, 100 ug/ml of SO. clearly reduced the presence of CD11b molecules on the cell surfaces by $\sim 30 \%$ (at an optimum $\sim 2-4 \mathrm{nM}$ CCL11 concentration) whereas none of the other test marine oil solutions showed any difference from the formulation control.

Apoptosis assay: We measured the effects of prophylactic treatments with $3 \mathrm{ug} / \mathrm{ml}$ ApoA-IV (positive control), $100 \mathrm{ug} / \mathrm{ml} \mathrm{SO}, \mathrm{FO}, \mathrm{KO}, \mathrm{SOHT}$, SOAT, SOBT and formulation vehicle (control) to modulate apoptosis in allergic human eosinophils. SO accelerated eosinophil apoptosis comparable to APOA-IV in allergic human cells. The percentage of live cells (annexin Vneg) decreased from 57.6\% \pm $4.5 \%$ in the control treatment to $31.5 \% \pm 2.3 \%$ in 3 ug/ml ApoA-IV-treated eosinophils (positive control) and $38.6 \% \pm 3.0 \%$ in $100 \mathrm{ug} / \mathrm{ml}$ SO-treated eosinophils.

Both ApoA-IV and SO also increased the percentage of apoptotic cells (annexinVpos) from $44.1 \% \pm 2.9 \%$ (control treatment) to $60 \% \pm 3.8 \%$ with $3 \mathrm{ug} / \mathrm{ml}$ ApoA-IV and $58.4 \% \pm 2.5 \%$ with $100 \mathrm{ug} / \mathrm{ml}$ So.

None of the other treatments showed any significant change in percentage of live cells (annexin Vneg) or apoptotic cells (annexin Vpos) as compared to the formulation control, as shown below in Table 3.

Table 3: Apoptosis assay of allergic human eosinophils (Annexin Vneg/Vpos)

\begin{tabular}{|c|c|c|}
\hline Treatment & Percent of Live Cells & Percent of Apoptotic Cells \\
\hline Control & $57.6 \pm 4.5$ & $64.1 \pm 2.9$ \\
\hline APOA-IV & $31.5 \pm 2.3$ & $58.4 \pm 2.5$ \\
\hline SO & $38.6 \pm 3.0$ & $45.1 \pm 3.7$ \\
\hline FO & $52.1 \pm 4.3$ & $43.9 \pm 3.1$ \\
\hline SOHT & $57.0 \pm 3.8$ & $45.8 \pm 3.2$ \\
\hline SOAT & $60.9 \pm 3.3$ & $49.2 \pm 3.0$ \\
\hline KO & $53.2 \pm 3.6$ & $46.1 \pm 2.3$ \\
\hline SOBT & $59.5 \pm 2.7$ & \\
\hline
\end{tabular}

\section{DISCUSSION}

In this study, we have shown that enzymatically extracted salmonid oil (SO) at $100 \mathrm{ug} / \mathrm{ml}$ is comparable to apolipoprotein A-IV at $3 \mathrm{ug} / \mathrm{ml}$ at modulating eosinophil effector function in allergic human peripheral blood eosinophils. 
Specifically, its shown that: 1) SO at $100 \mathrm{ug} / \mathrm{ml}$ inhibited eosinophil response to chemoattractant CCL11 in a Shape Change assay; 2) SO at $100 \mathrm{ug} / \mathrm{ml}$ inhibited eosinophil response to chemoattractant CCL11 in an integrin (CD11b) surface upregulation assay; and 3) SO enhancedapoptosis in eosinophils sourced from allergic individuals and hence enzymatically extracted salmonid oil shows promising anti-allergic potential for the treatment of eosinophil modulated inflammations.

To better delineate the source of the eosinophil effector function modulation observed after prophylactic treatment with the enzymatically extracted salmonid oil, we co-tested commercially available fish oil and krill oil, as representative marine oils with similar fatty acid profiles. Our results showed that the fish oil had overall very low eosinophil effector function modulation and the krill oil had no effect.

In the eosinophil shape change assay at the peak response concentration of $0.75 \mathrm{nM}$ CCL11, APOA-IV showed a $-12.2 \%$ decrease from control with the salmonid oil showing a similar $-9.8 \%$ decrease. Fish oil and krill oil showed a much lower modulation of $4.9 \%$ and $-2.4 \%$ respectively.

In the eosinophil mobilization assay at the peak response concentration of $5 \mathrm{nM}$ CCL11, APOA-IV showed a $-14.9 \%$ decrease from control with the salmonid oil showing a slightly better $-17.0 \%$ decrease. Here fish oil showed almost no modulation at $-2.0 \%$ decrease and krill oil showed no response $(+0.7 \%)$.

In the eosinophil apoptosis assay, APOA-IV showed a $-45.3 \%$ decrease in live cells and a $+36.1 \%$ increase in apoptotic cells from control and the salmonid oil showed a similar $-33.0 \%$ decrease in live cells and $a+32.4 \%$ increase in apoptotic cells from control. Fish oil and krill oil showed a significantly much reduced response of $-9.5 \%$ and $-7.6 \%$ decrease in live cells and $+2.3 \%$ and $+11.6 \%$ increase in apoptotic cells, respectively.

We posit that these results show that eicosapentaenoic acid (EPA) and docosahexaenoic acid (DHA), which are the dominant fatty acid active ingredients in fish oils, have little to no eosinophil effector function modulation in allergic human peripheral blood eosinophils.

In a further effort to better understand the source of the high eosinophil modulating activity observed in the salmonid oil, we treated this oil to processing conditions normally used in fish oil production to measure the deleterious effect such processing treatments might have on pure fresh fish oils in modulating allergic eosinophils.

In the eosinophil shape change assay at the peak response concentration of $0.75 \mathrm{nM} \mathrm{CCL11,} \mathrm{the} \mathrm{heat-}$ treated salmonid oil showed a similar decrease from control as the fish oil at $-4.1 \%$, while the acid-treated salmonid oil and base treated salmonid oil effectively showed no change from control at $-1.6 \%$ and $-0.8 \%$ respectively.

In the eosinophil mobilization assay at the peak response concentration of $5 \mathrm{nM} \mathrm{CCL11,} \mathrm{all} \mathrm{three}$ treatments, heat-treated, acid-treated and basetreated effectively showed no change from control at $-0.7 \%,-1.4 \%$ and $-0.7 \%$ respectively.

In the eosinophil apoptosis assay, all three treatments, heat-treated, acid-treated and basetreated effectively showed no change from control 
for decrease in live cells or increase in apoptotic cells at $-1.0 \%,+5.7 \%,+3.3 \%$ and $-0.4 \%,+3.8 \%,+4.5 \%$ respectively.

We posit that these processing conditions are destroying the hitherto unidentified components present in the enzymatically extracted salmonid oil to various degrees. No change in the fatty acid profile was noted between the unheated and heated salmonid oil indicating again that the major fatty acid components are not playing a role in eosinophil effector function modulation.

\section{CONCLUSION}

These results clearly show the promise of enzymatically extracted salmonid oil as a prophylactic therapeutic treatment for allergic as well as infective respiratory inflammation. Our on-going guinea pig dosing studies and human clinical trials with eosinophilic Covid-19 patients will be reported on in the future.

List of Abbreviations: SO, enzymatically extracted salmonid oil; FO, $18 \%$ docosahexaenoic acid/12\% eicosapentaenoic acid Fish Oil; KO, Krill Oil; SOHT, Heat-treated SO; SOAT, Acid-treated SO; SOBT, Basetreated SO; AHPBE, Allergic Human Peripheral Blood Eosinophils; APOA-IV, Apolipoprotein A-IV;

Authors' Contributions: Bomi Framroze designed and carried out the cellular research and has primary responsibility for the final content. Henriette Heggdal carried out assay article preparations and specifications and edited and approved the final version of the manuscript.
Competing Interests: Bomi Framroze is consulting CSO and Henriette Heggdal is Senior Laboratory Manager for Hofseth Biocare ASA.

\section{REFERENCES}

1. Mickleborough, T.D., Lindley, M.R., Ionescu, A.A., Fly, A.D. (2006) Protective Effect of Fish Oil Supplementation on Exercise-Induced Bronchoconstriction in Asthma. Chest. 129(1), 39-49

2. Stoodley, I., Garg, M. Scott, H., Macdonald-Wicks, L., Berthon, B., Lisa Wood, L. (2019) Higher Omega-3 Index Is Associated with Better Asthma Control and Lower Medication Dose: A Cross-Sectional Study. Nutrients 12, 74

3. Tang, H., Xun, P., He, K. (2013) Fish and Fish Oil Intake in Relation to Risk of Asthma: A Systematic Review and Meta-Analysis. Plos One. 8:e80048

4. Lang, J.E.,, Edward B. Mougey, E.B., Hossain, M.J., Livingston, Babu Balagopal, F.P., Langdon, S., Lima, J.J. (2019) Fish Oil Supplementation in Overweight/Obese Patients with Uncontrolled Asthma. A Randomized Trial. Annals Am. Thoracic Soc. 16(5), 554-562

5. Øien, T., Schjelvaag, A., Storrø, O., Johnsen, R., Simpson, M. (2019) Fish Consumption at One Year of Age Reduces the Risk of Eczema, Asthma and Wheeze at Six Years of Age. Nutrients 11, 1969

6. Papamichael, M.M., Shrestha, S.K., Itsiopoulos, C., Erbas, B. (2018) The role of fish intake on asthma in children: A meta-analysis of observational studies. Pediatric Allergy and Immunology. 29, 350-360

7. Hogan, S.P. (2007) Recent advances in eosinophil biology. Int Arch Allergy Immunol. 143(Suppl 1), 3-14

8. Simon, D, Braathen, L.R., Simon, H.U. (2004) Eosinophils and atopic dermatitis. Allergy. 59, 561-570

9. Wedemeyer, J., Vosskuhle, K. (2008) Role of gastrointestinal eosinophils in inflammatory bowel disease and intestinal tumours. Best Pract Res Clin Gastroenterol. 22, 537-549

10. Parra, A., Sanz, M.L., Vila, L., Prieto, I., Dieguez, I., Oehling, A.K. (1999) Eosinophil soluble protein levels, eosinophil peroxidase and eosinophil cationic protein in 
asthmatic patients. J Investig Allergol Clin Immunol. 9, $27-34$

11. Park, Y.M., Bochner, B.S. (2010) Eosinophil survival and apoptosis in health and disease. Allergy Asthma Immunol Res. 2, 87-101

12. Hahn, C., Islamian, A.P., Renz, H., Nockher, W.A. (2006) Airway epithelial cells produce neurotrophins and promote the survival of eosinophils during allergic airway inflammation. Journal of Allergy and Clinical Immunology 117(4), 787-794

13. Agache, I. (2019) Severe asthma phenotypes and endotypes. Seminars in Immunology 46, 101301

14. Chung, K.F. (2013) New treatments for severe treatment-resistant asthma: targeting the right patient. The Lancet Respiratory Medicine 1(8), 639-652

15. Hallsworth, M.P, Twort, C.H.C, Lee, T.H., Hirst, S.J. (2001) beta2-Adrenoceptor agonists inhibit release of eosinophil-activating cytokines from human airway smooth muscle cells British Journal of Pharmacology $132,729-741$

16. Hutcheson, P.S., Schubert, M.S., Slavin, R.G. (2010) Distinctions between allergic fungal rhinosinusitis and chronic rhinosinusitis. Am J Rhinol Allergy. 24, 405-408

17. Schratl, P., Sturm, E.M., Royer, J.F., Sturm, G.J., Lippe, I.T., Peskar, B.A. (2006) Hierarchy of eosinophil chemoattractants: role of p38 mitogen-activated protein kinase. Eur J Immunol 36, 2401-2409

18. Konya, V., Ullen, A., Kampitsch, N., Theiler, A., Philipose, S., Parzmair, G.P. (2013) Endothelial E-type prostanoid 4 receptors promote barrier function and inhibit neutrophil trafficking. J Allergy Clin Immunol 131, 532540 